\title{
Effect of Strain Hardening on Precipitation Kinetics in ATI 718Plus
}

\author{
Bilal Hassan ${ }^{1, a^{*}}$, Yann Jansen ${ }^{2, b}$, Sebastien Nouveau ${ }^{1, c}$ and Jonathan \\ Corney ${ }^{3, d}$ \\ ${ }^{1}$ University of Strathclyde, Advanced Forming Research Centre, 85 Inchinnan Drive, Inchinnan, \\ Renfrewshire, PA4 9LJ, United Kingdom \\ ${ }^{2}$ Aubert \& Duval, 75 Boulevard de la Liberation, BP 173, 09102 Pamiers, France \\ ${ }^{3}$ University of Strathclyde, Department of Design, Manufacture and Engineering Management, 75 \\ Montrose Street, Glasgow, G1 1XJ, United Kingdom \\ abilal.hassan@strath.ac.uk, byann.jansen@eramet-aubertduval.com, \\ csebastien.nouveau@eramet-aubertduval.com, djonathan.corney@strath.ac.uk
}

Keywords: eta phase, $n$ phase, precipitation kinetics, strain hardening, ATI 718Plus

\begin{abstract}
ATI 718Plus components are manufactured by forging a wrought billet in stages to obtain the desired geometry and microstructure. Parts are then heat treated to optimized proportions of $\gamma^{\prime}$ and $\eta$ phases. $\eta$ phase is a plate-like phase that precipitates on the grain boundaries of ATI 718Plus, similar to $\delta$ phase in Inconel 718 . However, the complete kinetic behaviour of $\eta$ phase precipitation during forging and heat treatment is still not fully understood. This paper investigates the effects of strain hardening on $\eta$ phase precipitation kinetics in ATI 718Plus. This is achieved through the use of isothermal hot compression tests and heat treatment. Strain hardening was found to affect the $\eta$ precipitation kinetics considerably. The results reported are a contribution to a fuller understanding of this important process.
\end{abstract}

\section{Introduction}

ATI 718Plus is polycrystalline nickel based superalloy which has a variety of potential uses within aerospace gas turbine engines in the form of both static and rotating components. It enjoys a $55^{\circ} \mathrm{C}$ temperature capability advantage over Inconel 718 [1]. It also has good processing characteristics which makes it a potential replacement for more expensive $\gamma$ ' strengthened alloys such as Waspaloy or Udimet 720 [2,3].

Inconel 718 is primarily strengthened by the metastable $\gamma$ ' phase $\left(\mathrm{Ni}_{3} \mathrm{Nb}, \mathrm{D}_{22}\right.$, body centered tetragonal) [4], whereas the primary strengthening phase of ATI 718Plus is $\gamma^{\prime}\left(\mathrm{Ni}_{3}(\mathrm{Al}, \mathrm{Nb}, \mathrm{Ti}), \mathrm{L1}_{2}\right.$, face centered cubic) [5], which is the source of the higher temperature capability over Inconel 718. Through sufficient heat treatment, a secondary phase can be precipitated at the grain boundaries of the austenitic $\gamma$ matrix. This can be used to control grain growth during hot working processes at temperatures below the solvus temperature. This control of grain growth is achieved via a microstructural mechanism known as Zener pinning [6]. Within ATI 718Plus, this secondary phase is the $\eta$ phase $\left(\mathrm{Ni}_{6}(\mathrm{Al}, \mathrm{Ti}) \mathrm{Nb}, \mathrm{D0}_{24}\right.$, hexagonal closed packed) [7], whereas in Inconel 718, the secondary phase is $\delta$ phase $\left(\mathrm{Ni}_{3} \mathrm{Nb}, \mathrm{D} 0_{\mathrm{a}}\right.$, orthorhombic) [4]. It has been reported that very thin layers of $\delta$ phase are found within the $\eta$ phase precipitates, although these layers are only a few atoms thick [7].

It is known that grain boundary precipitation can, in small amounts, reduce high temperature notch sensitivity [8], resist intergranular crack propagation and improve grain size control during hot working operations [9]. Although, excessive amounts of $\delta$ phase are detrimental to the alloys' mechanical properties [7].

Previous studies have shown that the strain from deformation does affect the precipitation kinetics of grain boundary precipitates in nickel based superalloys. This is especially important for manufacturers since the amount of $\delta$ phase that is precipitated depends on the thermomechanical 
history of the material. Chamanfar et al [10] found that in a non-isothermal forged billet of Inconel 718 , the $\delta$ phase precipitation during a subsequent heat treatment was considerably varied from the centre to the edge of the as-forged billet. This can be attributed to the variation in stress applied across the billet, although the data is found to be highly scattered. It could also be attributed to differences in thermal heat loss across the billet from the centre to the billet.

Liu et al [11] and Mei et al [12] carried out an extensive study of the effect of cold rolling on the precipitation behavior of the $\delta$ phase within Inconel 718. It was found that cold rolling promotes the precipitation of $\delta$ phase. The authors found that at $960^{\circ} \mathrm{C}$, the recrystallisation of the $\gamma$ matrix is completed well before the commencement of $\delta$ precipitation. However, the increase in $\delta$ phase precipitation kinetics from cold rolling is still observed. Due to the recrystallisation, dislocations created from cold rolling have been eradicated before the start of precipitation. Therefore, the theory that dislocations created from cold rolling increases the density of nucleation sites and increases the diffusivities of precipitate forming elements cannot be applied here. Instead, the authors attributed the faster kinetics of $\delta$ phase to niobium segregation. At lower temperatures in which no or less recrystallisation occurs, the faster precipitation kinetics are a result of both niobium segregation and higher dislocation density from deformation, which leads to even faster $\delta$ precipitation kinetics [11].

Although relatively little literature exists regarding the effect of deformation on precipitation kinetics within nickel superalloys, some authors have found that increasing the level of strain also causes increased $\eta$ phase precipitation within ATI 718Plus [13,14]. Casanova et al [15] found that within the microstructure of components made with ATI 718Plus, two main morphologies co-exist together; coarse plates and thin lamellae, and the origin of these were investigated by the author. $\eta$ phase precipitates are present within the microstructure of the billet prior to forging as coherent thin lamellae. During sub-solvus forging (with the $\eta$ solvus temperature being approximately $998^{\circ} \mathrm{C}$ [16]), these precipitates are deformed and unpinned from their initial nucleation locations. As a result, the interface between the $\eta$ precipitates and the $\gamma$ matrix becomes incoherent, which gives the $\eta$ precipitates increased mobility. During following processing operations, these precipitates develop a thicker coarser morphology. Also, their direction is more aligned with the local forging flow, which is an indication of their increased mobility. However, during the post-forging processing operations, new coherent $\eta$ phase precipitates are formed. Since they are coherent, they grow into a fine lamellar morphology and thus, two morphologies of $\eta$ phase exist within the final microstructure.

Another study from the same author [16] found that these morphologies even exist in different locations within the wrought billet during heating before sub-solvus forging takes place. The surface of the billet had coarse $\eta$ plates which are result of a high lattice rotations and high dislocation densities the come from the production process of the wrought billet. On the other hand, the centre of the billet consisted of large recrystallised grains, which meant that there was no residual strain in these zones. As a result, the precipitates in the billet centre grew coherently into thin lamellae.

\section{Materials and Experimental Methods}

For this study, the ATI 718Plus material was produced and manufactured by ATI and then supplied by Aubert \& Duval. The material was melted twice; first vacuum induction melted followed by vacuum arc remelting. The material was then supplied in the form of an extruded bar which had undergone a heat treatment of $954^{\circ} \mathrm{C}$ for 1 hour followed by air cooling. This had ensured that the material was fully recrystallised and strain free. The surface was peeled and polished. The elemental composition of the material is shown below in Table 1 .

Table 1 - Elemental composition of the material used

\begin{tabular}{|c|c|c|c|c|c|c|c|c|c|c|c|}
\hline $\mathrm{Cr}$ & $\mathrm{Co}$ & $\mathrm{Fe}$ & $\mathrm{Mo}$ & $\mathrm{W}$ & $\mathrm{Nb}$ & $\mathrm{Al}$ & $\mathrm{Ti}$ & $\mathrm{P}$ & $\mathrm{B}$ & $\mathrm{C}$ & $\mathrm{Ni}$ \\
\hline 18.00 & 9.17 & 9.35 & 2.69 & 1.03 & 5.50 & 1.46 & 0.75 & 0.005 & 0.005 & 0.02 & $\mathrm{Bal}$ \\
\hline
\end{tabular}


For the strain free precipitation kinetics, samples were cut from the as-received bar and heat treated at different temperatures and times, ranging from $850^{\circ} \mathrm{C}$ to $975^{\circ} \mathrm{C}$ and from 30 minutes to 12 hours. Prior to this, the as-received material is heat treated at $990^{\circ} \mathrm{C}$ for 180 minutes and water quenched to produce a 'clean' microstructure in which all initial $\eta$ phase particles are dissolved. A furnace was used to perform the heat treatments with thermocouples placed as close as possible to the samples to ensure an accurate temperature reading. After heat treatment, the samples were then water quenched within 5 seconds. Microstructural images are taken for each sample via the use of a scanning electron microscope.

For the deformed material, isothermal compression tests were performed at 0.6 global strain with a strain rate of $0.1 \mathrm{~s}^{-1}$. This was performed using a Zwick HA250 material testing machine. The compressed samples are then machined into smaller samples and are heat treated at $950^{\circ} \mathrm{C}$ for times of $0.5,1,3$ and 12 hours.

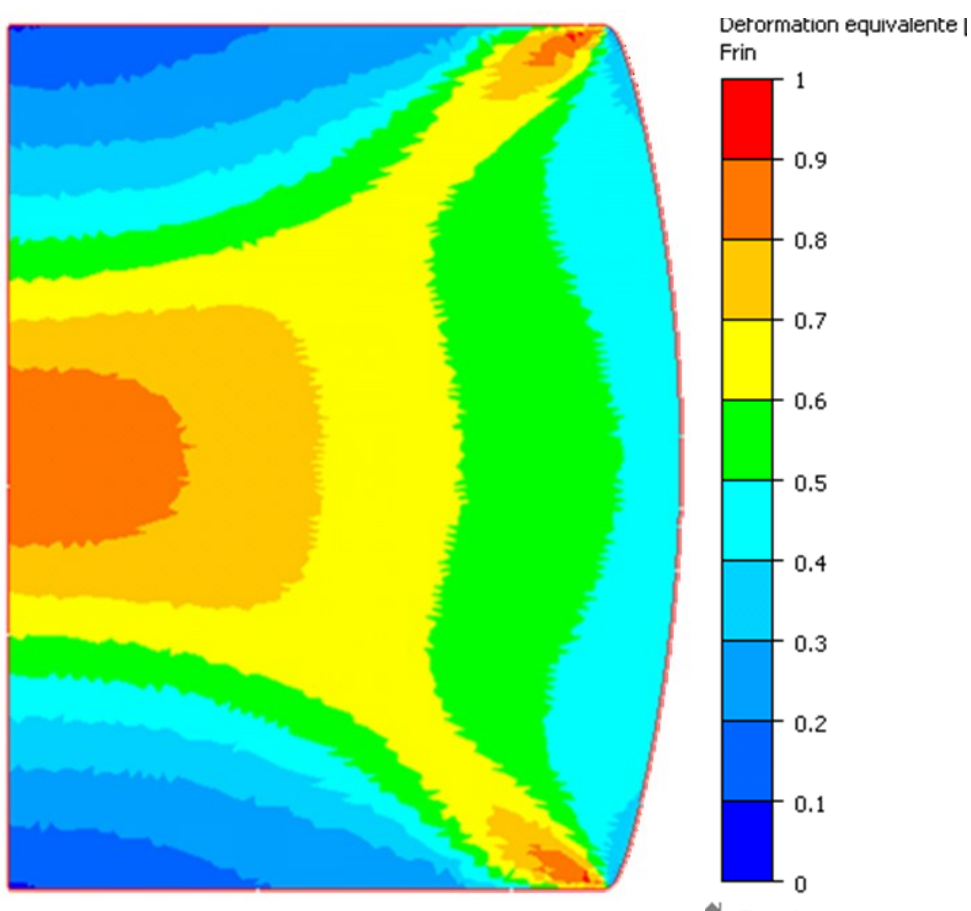

Figure 1 - Strain map of isothermal compression test from DEFORM software

Using the flow stress data from the compression tests, a strain map is produced using the DEFORM software (Figure 1). Within the compressed sample, local strains of $0.2,0.4$ and 0.6 are present within the sample. Scanning electron microscopy (backscattered mode, $20 \mathrm{kV}, 4.5$ spot size) is then performed at these local strains at $3000 \mathrm{X}$ magnification. These images are then thresholded using the Image J software package to obtain an approximation of the $\eta$ phase area fraction. EBSD is utilized to determine the initial grain size of the as-received material and after the heat treatment at $990^{\circ} \mathrm{C}$ for 180 minutes.

\section{Results and Discussion}

The EBSD maps from the as-received material and the 'clean' material are shown in Figure 2. The average grain size of the as-received material was $13.2 \mu \mathrm{m} \pm 5.3 \mu \mathrm{m}$ (standard deviation), while after the 180 minute heat treatment at $990^{\circ} \mathrm{C}$, the grain size became $12.8 \mu \mathrm{m} \pm 4.7 \mu \mathrm{m}$. Therefore, the grain size measurements show that the grain size has remained somewhat constant after $990^{\circ} \mathrm{C}$ heat treatment after 180 minutes. The EBSD grain size measurements have not included twin boundaries. 


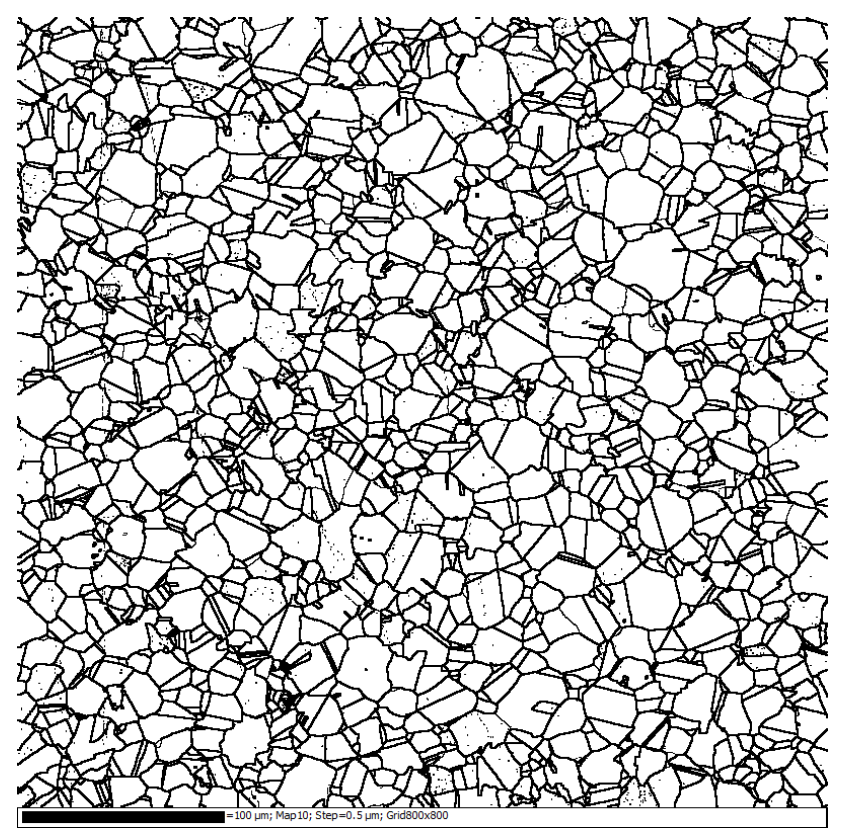

(a)

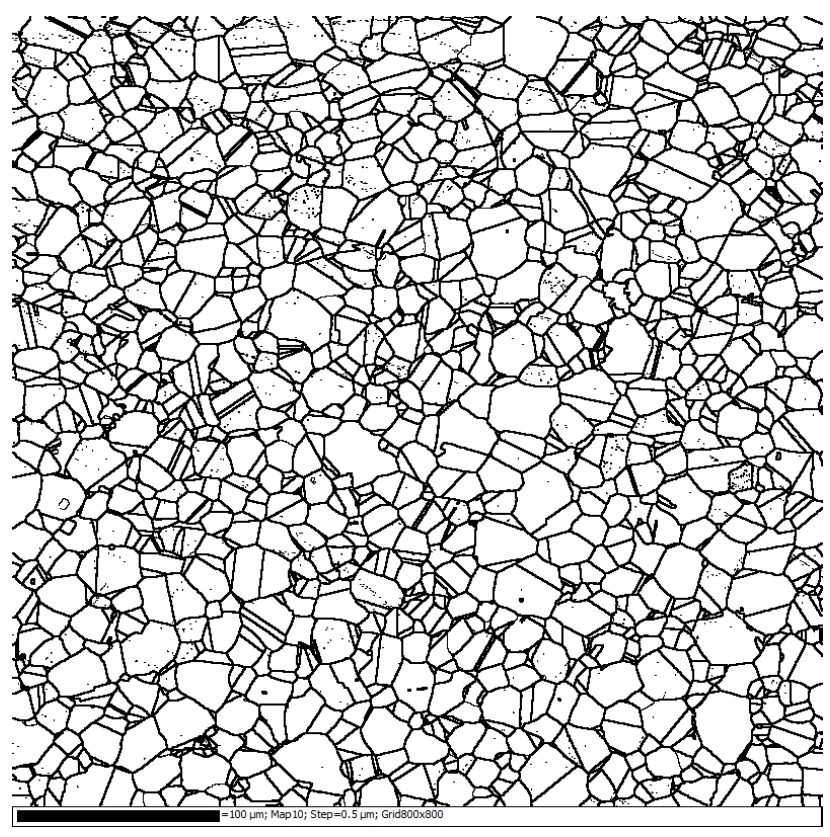

(b)

Figure 2 - EBSD map of (a) as-received material (b) after 180 minute heat treatment at $990^{\circ} \mathrm{C}$

Compression tests were performed at $0.1 \mathrm{~s}^{-1}$ strain rate and then machined into smaller samples. These samples were then heat treated for various times at $950^{\circ} \mathrm{C}$. Using a strain map, the precipitation kinetics was obtained at strains of $0.2,0.4$ and 0.6 , which was then compared to the precipitation kinetics at zero strain. Figure 3 displays the precipitation kinetics of strained and nonstrained material.

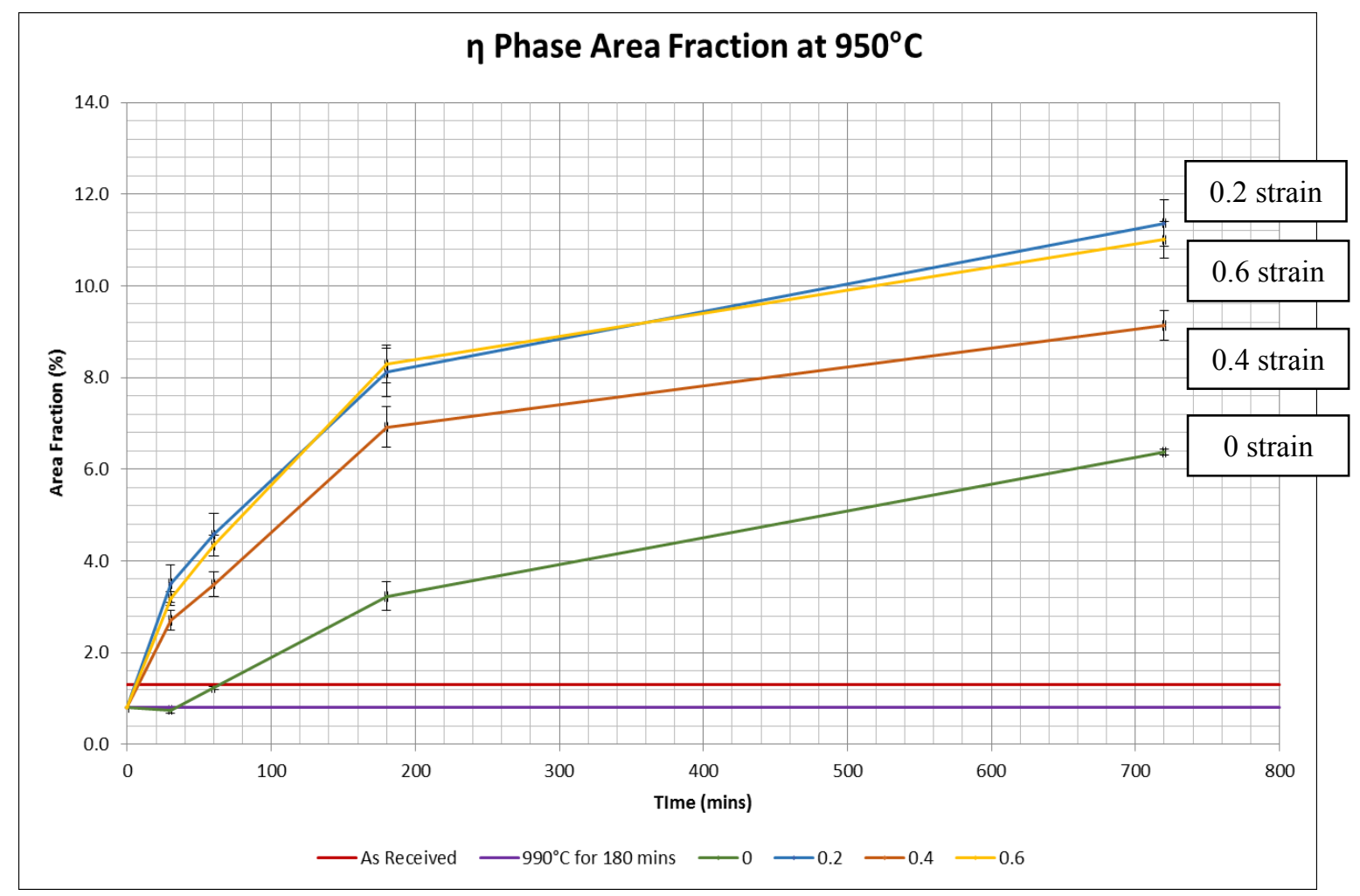

Figure 3 - Precipitation kinetics of both strained and strain free material 
From Figure 3, it is very clear that hot deformation has significantly increased the rate and amount of precipitation in comparison to the kinetics of strain free material. Interestingly, the amount of strain does not seem to impact the increase in precipitation at 0.2 and 0.6 strains. However, at 0.4 strain, the increase in precipitation is lower in comparison to 0.2 and 0.6 strain. The reason for this is currently unknown, and further work is required to explain this result.

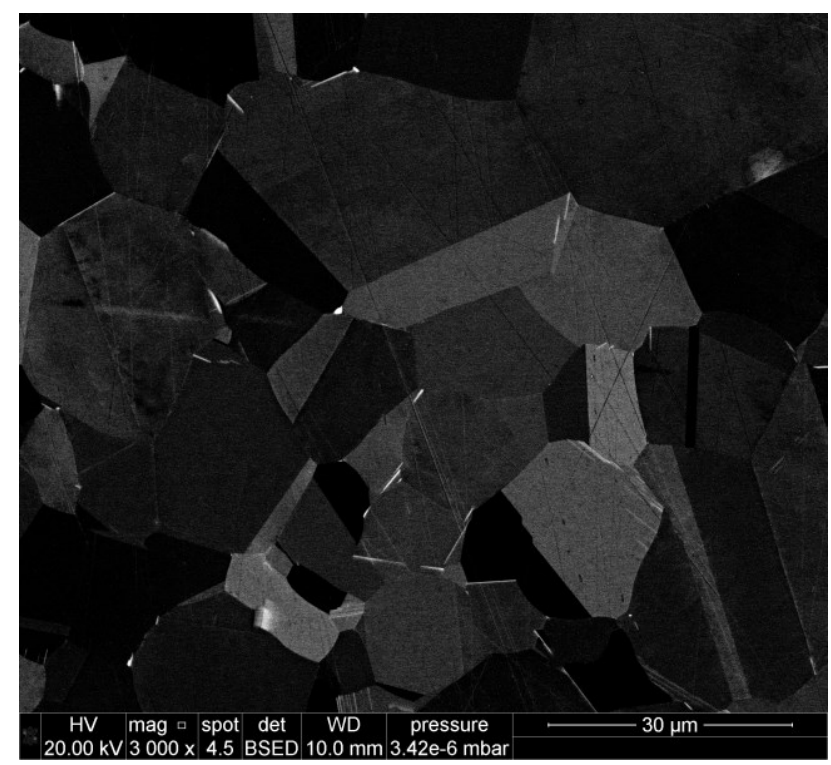

(a)

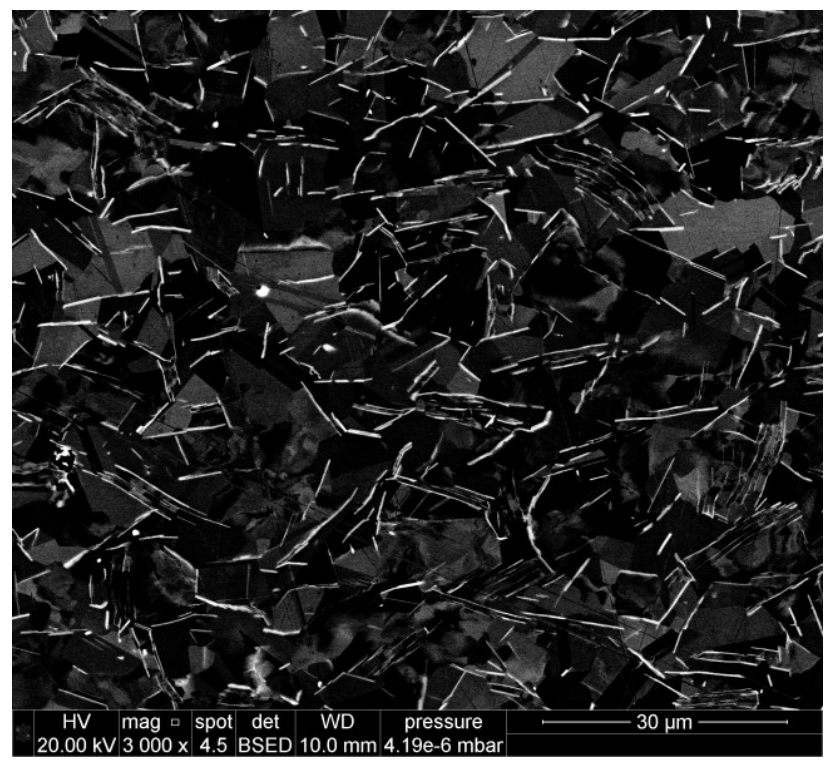

(c)

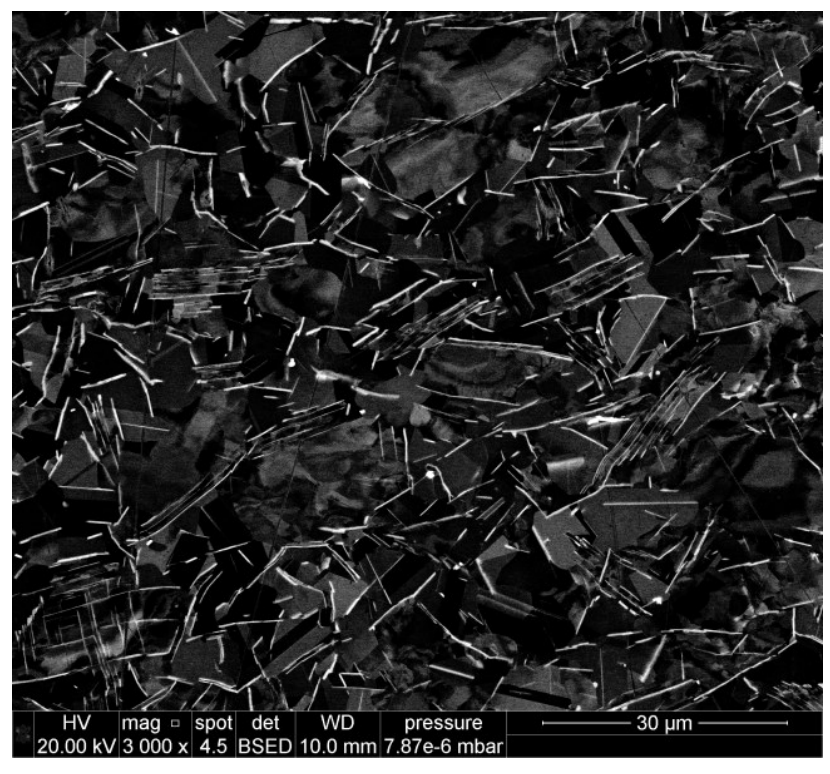

(b)

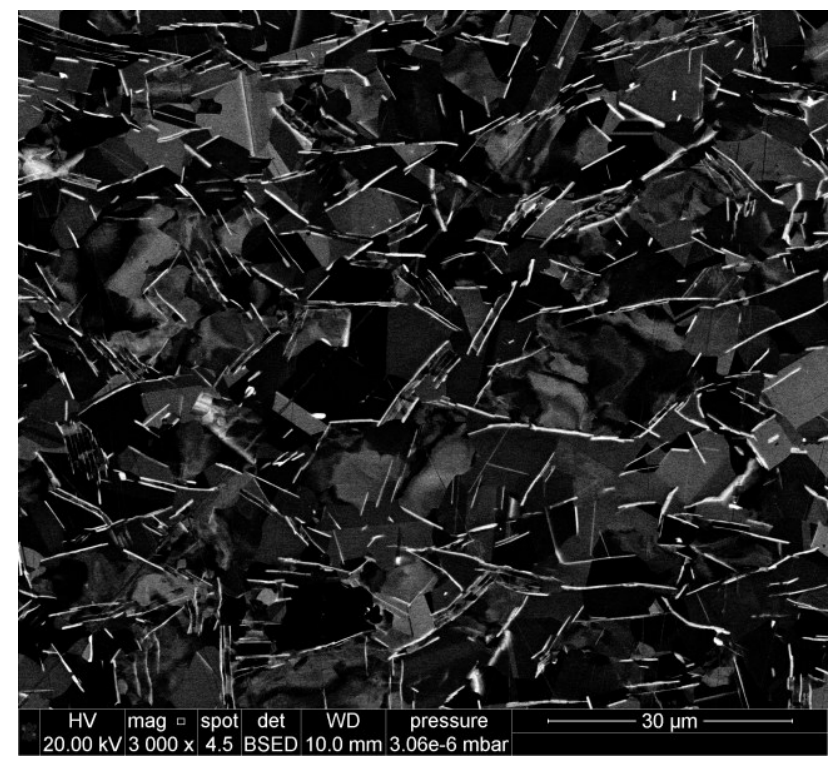

(d)

Figure 4 - Microstructures after: (a) $990^{\circ} \mathrm{C}$ for 180 minutes (b) 0.2 strain (c) 0.4 strain (d) 0.6 strain [(b), (c) and (d) at $950^{\circ} \mathrm{C}$ after 180 minutes]

In theory, grain boundary precipitation in both Inconel 718 and ATI 718Plus is promoted by increasing amounts of residual strain within the austenitic $\gamma$ matrix phase. However, in the current work, after hot deformation, the increase in $\eta$ phase precipitation kinetics is constant as a function of strain. As mentioned previously, there is little literature regarding the effect of hot deformation on grain boundary precipitation kinetics. However, in the current work, a proposal can be made to explain the data. It may be that the maximum amount of energy that the grain structure can store has been reached at 0.2 strain. Therefore, the amount of precipitation is constant from 0.2 strain 
onwards. The rest of the energy could be used to partially recrystallize the austenite matrix (as is observed in Figure 4), or it may be dissipated in the form of heat.

Another possibility is that heat treating after hot deformation could cause the annihilation of dislocations within the austenitic matrix. This lowers the amount of remaining dislocations and thus reduces the amount of potential nucleation sites for $\eta$ phase precipitation.

However, to obtain a fuller and complete understanding of the results, further in-depth work is required.

\section{Conclusions}

Precipitation kinetics of $\eta$ phase in ATI 718Plus increases after heat treatment following hot deformation. There is no difference in the level of precipitation at 0.2 and 0.6 strains, however the amount of precipitation is relatively reduced at 0.4 strain. Possible theories are provided to describe the experimental results but further work is required to confirm the explanation of the data.

\section{References}

[1] R. L. Kennedy: 'Allvac 718Plus, superalloy for the next forty years', Superalloys 718, 625, 706 and Derivatives, 2005, 1-14.

[2] R. M. Kearsey, J. Tsang, S. Oppenheimer and E. McDevitt: 'Microstructural Effects on the Mechanical Properties of ATI 718Plus ${ }^{\circledR}$ Alloy’ JOM., 2012, 64, (2), 241-251.

[3] E. A. Ott, J. Groh and H. Sizek: 'Metals affordability initiative: application of Allvac alloy 718Plus for aircraft engine static structural components', Superalloys 718, 625, 706 and Derivatives, 2005, 35-45.

[4] S. Azadian, L.-Y. Wei and R. Warren: 'Delta phase precipitation in Inconel 718', Mater. Charact., 2004, 53, (1), 7-16.

[5] L. Whitmore, M. R. Ahmadi, L. Guetaz, H. Leitner, E. Povoden-Karadeniz, M. Stockinger and E. Kozeschnik: 'The microstructure of heat-treated nickel-based superalloy 718Plus' Mater. Sci. Eng. A., 2014, 610, (July 2014), 39-45.

[6] A. Agnoli, M. Bernacki, R. Logé, J. M. Franchet, J. Laigo and N. Bozzolo: 'Selective growth of low stored energy grains during $\delta$ sub-solvus annealing in the Inconel 718 nickel-based superalloy', Metall. Mater. Trans. A, 2015, 46, (9), 4405-4421.

[7] E. J. Pickering, H. Mathur, A. Bhowmik, O. M. D. M. Messé, J. S. Barnard, M. C. Hardy, R. Krakow, K. Loehnert, H. J. Stone and C .M. F. Rae: 'Grain-boundary precipitation in Allvac 718Plus', Acta Mater., 2012, 60, (6-7), 2757-2769.

[8] J. Andersson, S. Hatami and G. Sjöberg: 'Notch sensitivity and intergranular crack growth in the Allvac 718Plus superalloy', 18th ISABE Conf., 2007.

[9] W-D. Cao and R. L. Kennedy: 'Recommendations for Heat Treating Allvac 718Plus Alloy Parts', 2006.

[10] A. Chamanfar, L. Sarrat, M. Jahazi, M. Asadi, A. Weck and A. K. Koul: 'Microstructural characteristics of forged and heat treated Inconel-718 disks', Mater. Des., 2013, 52, 791-800.

[11] W. C. Liu, Z. L. Chen, and M. Yao: 'Effect of cold rolling on the precipitation behavior of $\delta$ phase in Inconel 718', Metall. Mater. Trans. A, 1999, 30, (1), 31-40

[12] Y. Mei, Y. Liu, C. Liu, C. Li, L. Yu, Q. Guo and H. Li: 'Effects of cold rolling on the precipitation kinetics and the morphology evolution of intermediate phases in Inconel 718 alloy', J. Alloys Compd., 2015, 649, 949-960.

[13] E. McDevitt: 'Effect of temperature and strain during forging on subsequent delta phase precipitation during solution annealing in ATI 718Plus alloy',7th International Symposium on Superalloy 718 and Derivatives, 2010, 307-319.

[14] O. Covarrubias, "Microstructural and mechanical effects of thermo-mechanical processing on ATI 718Plus contoured rings," Adv. Mater. Res., 2011, 278, 271-276.

[15] A. Casanova, N. Martín-Piris, M. Hardy and C. Rae: 'Evolution of secondary phases in alloy 
ATI 718Plus during processing', 2nd European Symposium on Superalloys and their Applications, 2014, 1-6.

[16] A. Casanova, M. Hardy and C. M. F. Rae: 'Morphology and kinetics of grain boundary precipitation in alloy ATI 718Plus', 8th International Symposium on Superalloy 718 and Derivatives, 2014, 573-586. 